\title{
The potential for extending Intcal04 using OIS-3 New Zealand sub-fossil Kauri
}

\author{
A. G. Hogg ${ }^{1}$, C. S.M. Turney ${ }^{2}$, J. G. Palmer ${ }^{3}$, L. L. K. Fifield ${ }^{4}$ and M. G. L. Baillie ${ }^{5}$ \\ 'Radiocarbon Dating Laboratory, University of Waikato, Hamilton, New Zealand; alan.hogg@waikato.ac.nz \\ ${ }^{2}$ GeoQuEST Research Centre, School of Earth and Environmental Sciences, University of Wollongong, Australia \\ ${ }^{3}$ Gondwana Tree-Ring Laboratory, Canterbury, New Zealand \\ ${ }^{4}$ Department of Nuclear Physics, Research School of Physical Sciences and Engineering, Australian National University, Canberra, Australia \\ ${ }^{5}$ Department of Archaeology and Palaeoecology, School of Geography, Archaeology and Palaeoecology, Queen's University, Belfast, UK
}

\section{Introduction}

Recent articles by Turney et al. (2006) and Balter (2006) publicized the current state of radiocarbon calibration beyond $20 \mathrm{kyr}$ BP. They stress the need for new calibration studies, which are critical for developing late Pleistocene chronologies for paleoclimate and archeological research. Peat bogs in Northland, New Zealand contain large numbers of sub-fossil kauri (Agathis australis) logs in discontinuous sequences ranging in age from a few hundred years to more than $60 \mathrm{kyr}$ BP. The buried trees are well preserved, often with their bark still attached and one has been found to contain more than 2000 rings. This article summarizes some current research being undertaken on the Northland sub-fossil Oxygen Isotope Stage (OIS)-3 (25 - 60 kyr BP) kauri resource by a team from New Zealand, Australia and the UK.

\section{Sampling}

OIS-3 "ancient kauri" logs are found in bogs scattered over a $300 \mathrm{~km}$ stretch of northern New Zealand, from about $34^{\circ} 50^{\prime}$ to $36^{\circ} 20^{\prime} \mathrm{S}$ (Palmer et al., 2006). Kauri is a highly valued timber species but past over-exploitation of living stands now means supplies are limited. The remarkable preservation state of the buried kauri and its inherent value has meant the wood is being harvested for commercial purposes. Our practice has been to take advantage of this and work alongside milling companies who use large earth moving machinery to mine the buried logs.

As the logs are extracted, we cut cross-sections from the base of the bole but above the root plate to avoid tree-ring distortion because of buttressing and flaring. Tree-ring samples are prepared and analyzed following well-documented dendrochronological techniques for ring-width measurement and cross-dating.

\section{Dendrochronological analysis}

Thus far, we have collected 167 cross-sections from 16 different pre-Holocene bog sites and 145 have been measured (Palmer et al., 2006). Several discontinuous floating chronologies have now been developed which in total span more than 10,000 years. The preliminary cross-dating has shown

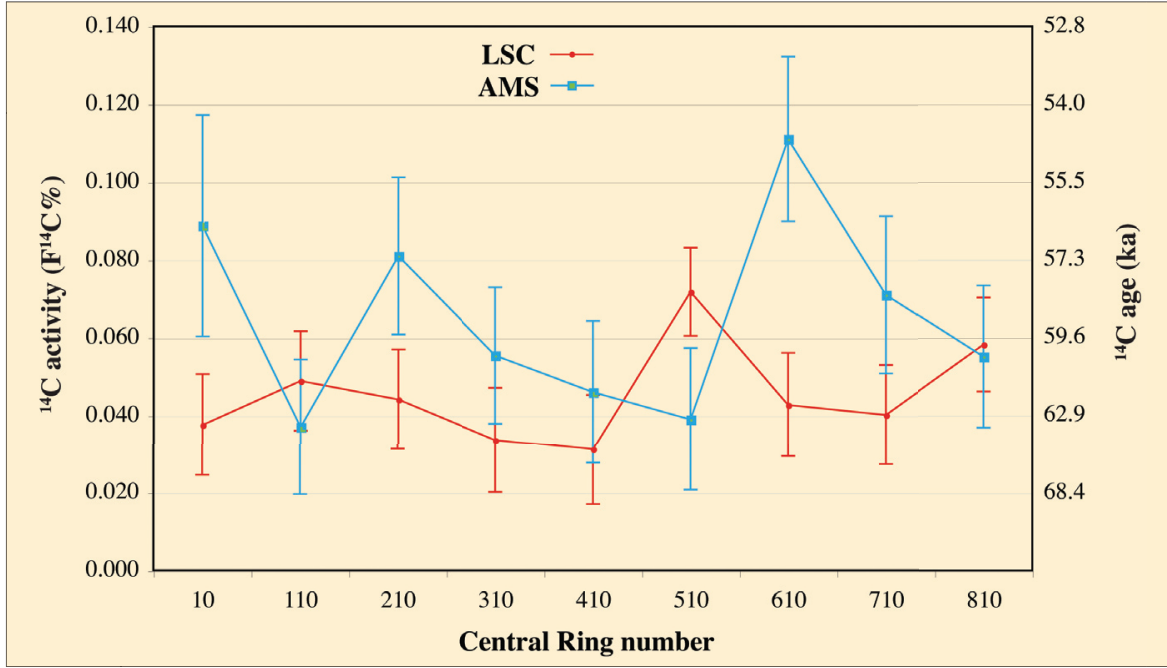

Figure 1: ${ }^{14} \mathrm{C}$ activities (F14C\%) for nine consecutive 100-ring blocks extracted from Vinac Farm, tree 6, by both LSC and AMS (data from Hogg et al., accepted).

that it is possible to cross-match between different trees from different locations (i.e. inter-site cross-matching). Furthermore, the spread in the radiocarbon ages obtained from within and between sites indicates that preservation did not take place during only one specific period of time. A possibility therefore exists for the development of long continuous sections of chronology within OIS-3.

\section{Radiocarbon dating}

As with many paleoecological studies, radiocarbon dating has been critical to understanding the relative time periods covered by the different tree-ring series. Integral to radiocarbon dating OIS-3 wood is the need to achieve reproducible, low-activity radiocarbon blanks and a robust, transparent methodology for assigning standard errors to ${ }^{14} \mathrm{C}$ ages that are close to the limit of the method. Although finite radiocarbon ages on organic carbon samples beyond $50 \mathrm{kyr}$ $\mathrm{BP}$ are becoming more common in the literature, few attempts have been made to demonstrate their accuracy or precision. We have established a robust methodology, permitting accurate and reproducible ${ }^{14} \mathrm{C}$ dates in the $50-60 \mathrm{kyr} \mathrm{BP}$ age range, by both high-sensitivity liquid scintillation counting (LSC) and accelerator mass spectrometry (AMS) methods (Hogg et al., submitted; Hogg et al., accepted; Turney et al., accepted).

The reproducibility of these methods can be seen in Figure 1. The graph shows
${ }^{14} \mathrm{C}$ activities for 9 consecutive 100-ring blocks of wood extracted from a sub-fossil kauri log (mean age of ca. 61 kyr BP) close to background age.

Of the 16 sub-fossil (pre-Holocene) kauri sites, 7 have returned finite radiocarbon ages from the a-cellulose wood fraction spanning the full range of OIS-3 (Fig. 2). Ages of 24.9 kyr BP, 27.8 kyr BP (Finlayson Farm) and 28.5 kyr BP (Omaha Flats) indicate that stands of kauri are preserved at the end of OIS-3 and the transition into OIS-2. In contrast, material obtained from sites such as Trig Rd (62.2 kyr) demonstrates that trees are available towards the limits of radiocarbon dating and towards the transition into OIS-4. In between these extreme dates, we have identified trees that fall throughout OIS-3, suggesting that climatic and environmental conditions were suitable for preserving material during this time period.

\section{Conclusions}

The determination of a reliable, calibrated timescale encompassing the full range of the radiocarbon dating method is crucial if we are to understand fully the mechanisms of climatic, archeological and environmental change through the last glacial period. Unfortunately, however, there is no internationally accepted radiocarbon calibration curve beyond $26 \mathrm{kyr}$ BP, largely due to inherent problems with the materials used. Ideally, dendrochronologically dated subfossil trees can provide annually resolved samples on an absolute timescale, with the 


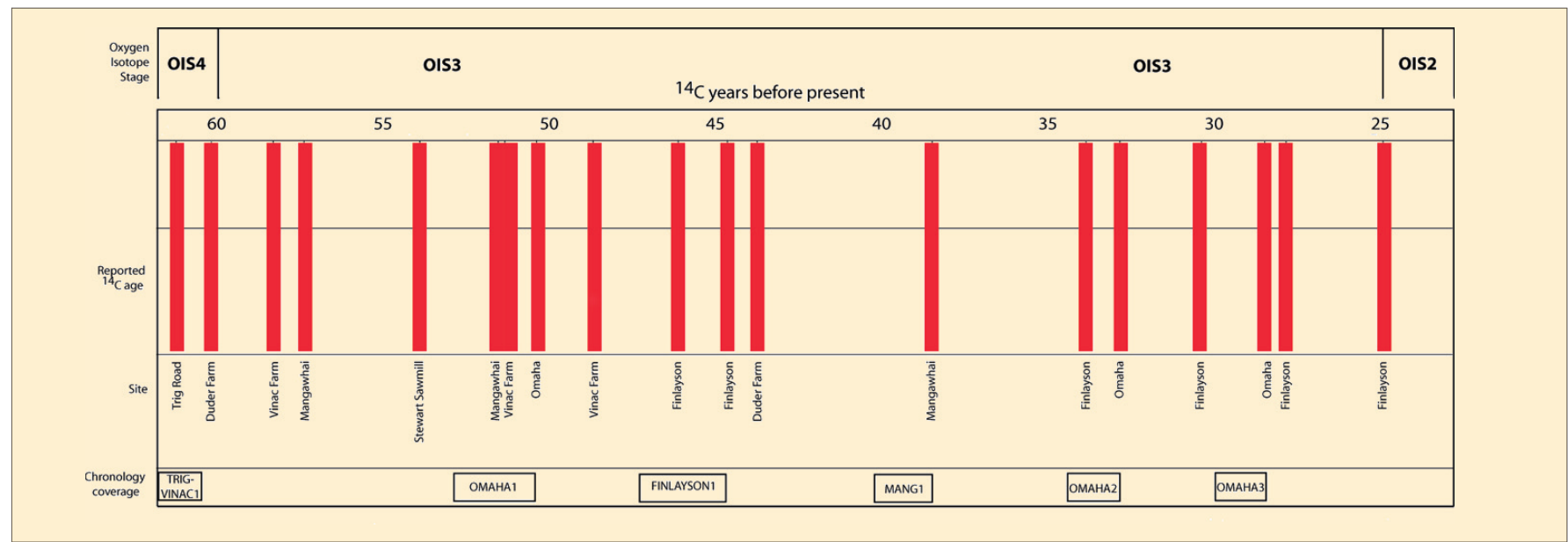

Figure 2: Chronologies and distribution of finite a-cellulose ${ }^{14} \mathrm{C}$ ages obtained on sub-fossil Agathis australis (Northland, New Zealand) - modified from Turney et al., accepted).

additional assurance that their carbon content is truly representative of atmospheric $\mathrm{CO}_{2}$ at the time of growth. The principal sources of uncertainty that have plagued other attempts at calibration in this time range are thereby avoided. We have shown the considerable potential of New Zealand kauri (Agathis australis) for developing long floating sections of calibration curve in the time period 26-60 kyr BP and the LSC and AMS techniques that are required to obtain precise and reproducible ages at these older time periods. It must be remembered that IntCal04 teams took approx. 30 years to build 26,000 years of chronology. Although significant progress has been made with the kauri, a considerable investment in both time and resources will be necessary if this enormous task is to be completed.

\section{References}

Balter, M., 2006: Radiocarbon dating's final frontier, Science, 313: 15601563.

Hogg, A.G., Fifield, L.K., Palmer, J.G., Turney, C.S.M., Galbraith, R. and Robertson, S.A., Robust radiocarbon dating of wood samples by high sensitivity liquid scintillation spectroscopy in the 50 - $70 \mathrm{ka}$ age range. Radiocarbon, submitted.
Hogg, A.G., Fifield, L.K., Palmer, J.G., Turney, C.S.M., Galbraith, R. and Robertson, S.B., Dating ancient wood by high sensitivity liquid scintillation counting and accelerator mass spectrometry - pushing the boundaries. Quaternary Geochronology, accepted.

Palmer, J., Lorrey, A., Turney, C.S.M., Hogg, A.G., Fifield, L.K., Baillie, M.G.L. and Ogden, J., 2006: Extension of New Zealand kauri (Agathis australis) tree-ring chronologies into Oxygen Isotope Stage (OIS)-3, Journal of Quaternary Science, 21(7): 779-788.

Turney, C.S.M., Fifield, L.K., Palmer, J.G., Hogg, A.G., Baillie, M.G.L., Galbraith, R., Ogden, J., Lorrey, A. and Tims, S.G., Towards a radiocarbon calibration for oxygen isotope stage 3 using New Zealand kauri (Agathis australis). Radiocarbon, accepted.

Turney, C.S.M., Roberts, R.G. and Jacobs, Z., 2006: Progress and pitfalls in radiocarbon dating, Nature, 443: doi: 10.1038/nature05214.

\section{Marine reservoir corrections and the calibration curve}

\section{R. W. Reimer And P. J. Reimer}

${ }^{14} \mathrm{CHRONO}$ Centre for Climate, the Environment, and Chronology, Queen's University Belfast, UK; r.reimer@qub.ac.uk

The surface ocean carbon reservoir is variable both spatially and temporally, causing calibration of radiocarbon dates of organisms that have taken up marine carbon to be fraught with uncertainty. The paucity of reservoir age data that existed in 1993 on the publication of the seminal paper on the technique (Stuiver and Braziunas, 1993) has been alleviated to some extent. The largest archive of published $\Delta \mathrm{R}$ data, which is located at http://calib. org/marine, now contains more than 800 entries (Fig. 1). However, these data are of varying usefulness in determining the apparent age of the ocean water where they were collected. The following paragraphs will outline the considerations to make in combining, or averaging, available data to form a $\Delta R$ estimate for a particular locality, focusing initially on Holocene samples for which modern day $\Delta R$ are likely to be valid. Recommendations for the improvement of data quality will be made, followed by a discussion of how time variability should be incorporated in $\Delta R$ values.

$\Delta R$ is calculated by obtaining independent calendar and radiocarbon ages

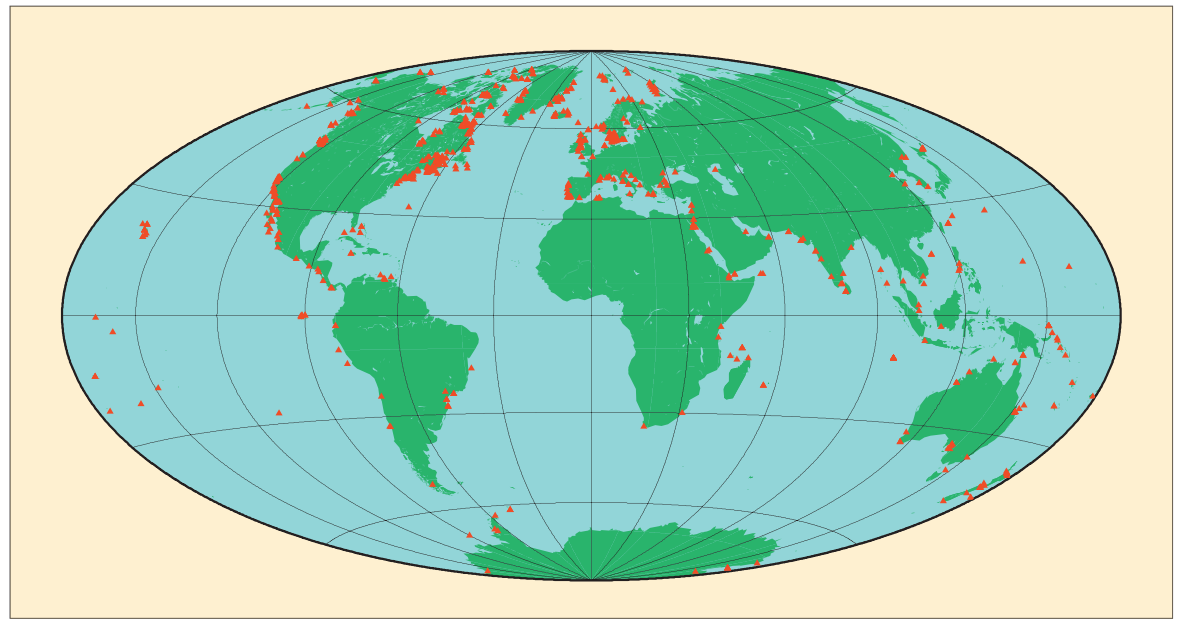

Figure 1: Locations of $\Delta R$ values in the Marine Reservoir Correction Database; $h$ ttp://calib.org/marine.

for an organism that has sampled marine carbon. The most straightforward method to obtain the calendar age is to ascertain the year of death of the organism from historical records. It may also be obtained by carbon dating a terrestrial sample that can be unambiguously paired with a marine sample. Modern (post bomb) samples are avoided for this purpose because the distribution and ocean uptake of ${ }^{14} \mathrm{C}$ derived from atmospheric weapons testing is highly variable. Once the cal age is known, it is used to look up a ${ }^{14} \mathrm{C}$ age in the 'global' marine calibration curve. The difference between this ${ }^{14} \mathrm{C}$ age and the measured ${ }^{14} \mathrm{C}$ age of the marine sample is defined as $\Delta R$. A Bayesian technique that relaxes the contemporaneity requirement between the terrestrial and marine samples has been developed (Jones and Nicholls, 2002) to quantify uncertainty in the match up of the calendar ages of the paired samples. 